\title{
Nola eragiten du 2-Interleukinak T-zelulen nukleoko proteinen fosforilazio mailan?
}

\author{
(How does interleukin-2 affect the phosphorylation state \\ of nuclear proteins in T-cells?)
}

Nerea Osinalde

Biokimika eta Biologia Molekularra Saila, Farmazia Fakultatea (UPV/EHU)

nerea.osinalde@ehu.eus

DOI: $10.1387 /$ ekaia.17655

Jasoa: 2017-02-27

Onartua: 2017-05-04

Laburpena: Immunoterapiaren helburua da gaixoen immunitate-sistema indartuz minbizia bezalako gaitz larriak menderatzea. Horretarako, gaixoak maiz 2-interleukina (IL-2) deitzen den konposatu batekin tratatzen dira, izan ere molekula honek berebiziko ahalmena baitauka T-zelulen edo T linfozitoen hazkuntza sustatzeko. Zoritxarrez, IL-2ren erabilerak albo kalte desatseginak eragiten ditu gaixoetan, eta hauek ekiditeko ezinbestekoa da IL-2k T-zeluletan eragiten dituen molekula mailako aldaketak sakon aztertu eta ulertzea. Zelulen gainazalera heltzen diren seinaleak zelulan barrena garraiatzen dira nagusiki proteinen behin behineko fosforilazioen bidez. Hori horrela, aurreko lan batean, IL-2k T linfozitoetan pizten dituen seinalizazio-bidezidorrak aztertu genituen zelulen zitoplasman fosforilatzen diren proteinak masa espektrometriaren bidez identifikatuz. Oraingo lan honetan berriz, masa espektrometriaren laguntzaz aztertu da IL-2k nola erregulatzen duen T-zelulen nukleoko proteinen fosforilazio maila, izan ere horrek zuzenean eragingo baitu geneen erregulazioan eta horrenbestez baita zelularen patuan ere. Esperimentu bera 3 aldiz errepikatu ostean, gutxienez behin identifikatu eta kuantifikatu dira lan honetan T-zelulen nukleoko proteinetan fosforilatutako 8.521 aminoazido, horietako haietako asko aurrez ezagutugabeak. Bestalde, ikusi da orkorrean berdinantzera mantentzen dela IL-2rekin tratatutako eta tratatu gabeko T-zeluletako fosforilazio maila. Halere, azpimarragarria da IL-2ren ondorioz 391 aminoazidoren fosforilazio maila nabarmen aldatzen dela T-zelulen nukleoetan. Etorkizunean egingo diren ikerkuntzek argituko dute zein den IL-2ren menpeko fosforilazio hauen esanahi biologikoa.

Hitz gakoak: IL-2, fosfoproteomika, nukleoa, T linfozitoa, fosforilazioa.

Abstract: Immunotherapy aims to fight against diseases such as cancer by boosting the immune system of the patients. For that purpose, patients are usually treated with a 
molecule called interleukin-2 (IL-2), which plays a pivotal role in modulating the immune system and specially in promoting the proliferation of T-cells. Unfortunately, administration of IL-2 is usually accompanied by severe side effects that must be overcome. To achieve this, it is mandatory to understand in detail the molecular effects triggered in T-cells upon IL-2 stimulation. It is known that signaling events initiated at the cell surface are mainly transduced inside the cell through transient phosphorylations occurring in distinct proteins. For that reason our previous study focused on dissecting the signaling pathways triggered in IL-2-treated T lymphocytes by studying the proteins that become tyrosine phosphorylation upon the stimuli using mass spectrometry. In the present study, we aimed to unveil how IL-2 modulates the phosphorylation status of the nuclear proteins in T-cells, which ultimately will affect gene expression and the fate of the cell. Following a quantitative mass spectrometry-based approach a total of 8,521 phosphorylated aminoacids were quantified at least in one of the 3 replicas of the same experiment that were performed. Whereas the phosphorylation levels of most phosphosites remained unaffected in IL-2-treated and untreated T-cells, the phosphorylation status of 391 phosphosites was found to be dramatically modulated upon IL-2 stimulation. Further investigation will unveil the biological significance of such findings.

Keywords: IL-2, phosphoproteomics, nucleus, T lymphocyte, phosphorylation.

\section{SARRERA}

Bi hitzetan esanda, puri-purian dagoen immunoterapiaren helburua honakoa da: gaixoaren immunitate-sistema indartu, honek pairatzen den gaitzari aurre egin diezaion [1,2]. Jada abian dira immunoterapian oinarritzen diren saio kliniko batzuk, hesteetako hantura [3], gaixotasun autoimmuneak [4-6] edota minbizia [7,8] menderatzea helburu dutenak. Gaixotasunei aurre egiteko estrategia iraultzaile hau, duela hiru hamarkada sortu zen, melanoma pairatzen zuen gaixo bati T-zelulen hazkuntza bultzatzen duen 2 -interleukina (IL-2) eman zitzaionean $[9,10]$. Tratamenduaren eraginkortasunak lehengoz frogatu zuen nahikoa dela $\mathrm{T}$ linfozitoen jarduera kitzikatzea, minbizia mota batzuk deuseztatzeko. Gaur egun, IL-2k jarraitzen du immunoterapia askoren osagai garrantzitsuenetakoa izaten [11-14], baina efektu desatseginak ere eragiten ditu gaixoetan $[15,16]$. Horregatik, premiazkoa da IL-2ren tratamenduak T-zelulengan duen eragina sakonago ezagutzea, terapia seguruagoak diseinatu ahal izateko.

70. hamarkadatik, hots, IL-2 aurkitu zenetik, makina bat ikerkuntzatalde aritu dira zitokina honek T-zeluletan nola eragiten duen hobeto ulertu nahian. Gaur egun badakigu IL-2 zelula-mintzean txertatuta dauden hartzaileekin lotu bezain laster, seinalea zelulan zehar barreiatzen dela, bereziki proteinetan gertatzen diren behin-behineko fosforilazio prozesuen bitartez [17-19]. Txanda-lasterketa baten korrikalari batek hurrengoari testigua ematen dionean bezala, proteina batek ondokoari eta honek aldi be- 
rean bere ondokoari fosfato talde bat txertatuz zelularen gainazalean pizten den seinalea zelula barrura sartzen eta hedatzen da. Hain zuzen ere, aurreko lan batean sakon aztertu genituen zitokinak T-zeluletan sustatzen dituen seinalizazio-sareak IL-2ren eraginez fosforilatzen diren proteinak masa-espektrometria bidez aztertuz [20,21].

Proteinetan gertatzen diren fosforilazio/desfosforilazioek seinalizaziosareetan ez ezik, geneen adierazpenean ere eragin handia daukate [22]. Ezaguna da IL-2k piztutako seinaleek nukleoraino helduta geneen adierazpena erregulatzen dutela. Esaterako, IL-2ren bidez kitzikatutako T-zeluletan STAT familiako kide batzuk fosforilatu egiten dira, besteak beste STAT3 eta STAT5. Horrekin batera, nukleora sartzen dira eta beraien itugeneen transkripzioa erregulatzen dute $[23,24]$. Adibide honek argi erakusten du oso garrantzitsua dela nukleoko proteinen fosforilazio maila erregulatzeko modua ezagutzea, eta lan honek horixe bera argitzea hartu du helburu.

Proteinen fosforilazioa ikertzea erronka handia izan da eta bere horretan jarraitzen du, besteak beste fosforilatutako proteinen populazioa erlatiboki oso txikia delako zelula osoaren aldean. Hain zuzen, izugarrizko bultzada eman dio fosforilatutako proteinen ikerkuntzari fosforilatutako proteinak edo proteina-zatikiak aberasteko tekniken garapenak $\left(\mathrm{TiO}_{2}\right.$, IMAC, SIMAC etab.) [25-27]. Esan beharrekoa da 3 direla proteina batean fosforilatuta egon daitezkeen aminoazidoak: serinak (S), treoninak (T) eta tirosinak (Y). Hortaz, proteina bat fosforilatuta dagoela jakitea interesgarria bada ere, are interesgarriagoa da jakitea zehazki zein aminoazido dauden fosforilatuta. Izan ere, proteina bakar baten baitan gerta daitezkeen fosforilazio ezberdinek zehaztuko baitute proteinaren patua $[28,29]$.

Gaur gaurkoz, masa-espektometria da fosforilatutako proteinetan eraldatuta dagoen aminoazidoa zehatz-mehatz zein den jakiteko tresnarik eraginkorrena. Oro har, masa-espektrometroak oso aparailu sofistikatuak dira eta zehaztasun handiz neurtzen dituzte molekulen masak. Fosforilatutako proteina batek fosforilatu gabekoak baino pisu handiagoa du, zehazki, fosfato talde bakoitzeko 98 Da gehiago. Horregatik, masa-espektrometroak masa-gehikuntza hori detektatzen duenean ondoriozta daiteke proteina fosforilatuta dagoela. Gainera, neurketa oso fina bada, zehaztu daiteke fosforilatu daitezkeen aminoazido guztietatik zeinek duen edo duten fosfato taldea [30,31]. Fosforilatutako proteinak edo aminoazidoak detektatzeaz gain, fosforilazioak kuantifika daitezke, eta jada makina bat estrategia garatu dira horretarako, besteak beste SILAC (Stable isotope labeling of aminoacids in cell culture) delakoa [32]. Beste teknika guztiekin alderatuz SILAC oso berezia da, zelulak hazten ari diren heinean markatzen baitira proteinak. Zehazki, zelula-populazio beraren bi lagin hartu eta bakoitza bere aldetik masa desberdina daukaten aminoazidoen eraginpean hazten dira eta behin laginetako proteina guztiak markatuta, bakoitzari tratamendu bat egokitzen 
zaio. Laginetako proteinak erauzi ostean, erauzkinak batu egiten dira eta lagin bakarra bailiran prozesatuko dira ordutik eta masa-espektrometroan aztertzen diren arte. Baldintza desberdinetako laginak beraien arteko masa diferentzia dela eta bereizten dira masa-espektrometroan. Aldi berean, laginek erakusten dituzten intentsitateak elkarrekin konparatuz, haien arteko kuantifikazio erlatiboa egiten da.

Ikerketa askok frogatu dute fosforilatutako proteinen aberastea, SILAC kuantifikazioa eta masa-espektrometria bidezko analisia konbinatzea oso egokia dela estimulu batek proteinen fosforilazioan daukan eragina era masiboan ikertzeko [33-36]. Horrenbestez, lan-fluxu honen abantailez baliatu gara IL-2k T-zelulen nukleoko proteinen fosforilazio maila nola erregulatzen duen zehazteko [37].

\section{EMAITZAK}

IL-2k T-zelulen nukleoko proteinen fosforilazio maila nola erregulatzen duen zehazteko, 1. irudian adierazitako prozedura erabili genuen. $\mathrm{T}$ linfozitoen populazio beraren bi lagin izanik, bakoitza aminoazidoen aldaera arin edo astunetan hazi ziren; marka arinenarekin hazitako zelulak kitzikatu gabe utzi ziren kontrol gisa erabiltzeko, eta astunarekin hazitakoak aldiz, IL-2z kitzikatu ziren. Ondoren, nukleoak aberastu, proteinak erauzi, 1:1 proportzioan nahastu eta tripsinaz ebaki ziren. Lortutako proteina zatikiak, hots peptidoak, $\mathrm{TiO}_{2}$-dun esferatxoekin inkubatuz fosforilatutako peptidoak isolatu ziren eta azkenik hauek masa-espektrometria bidez analizatu ziren.

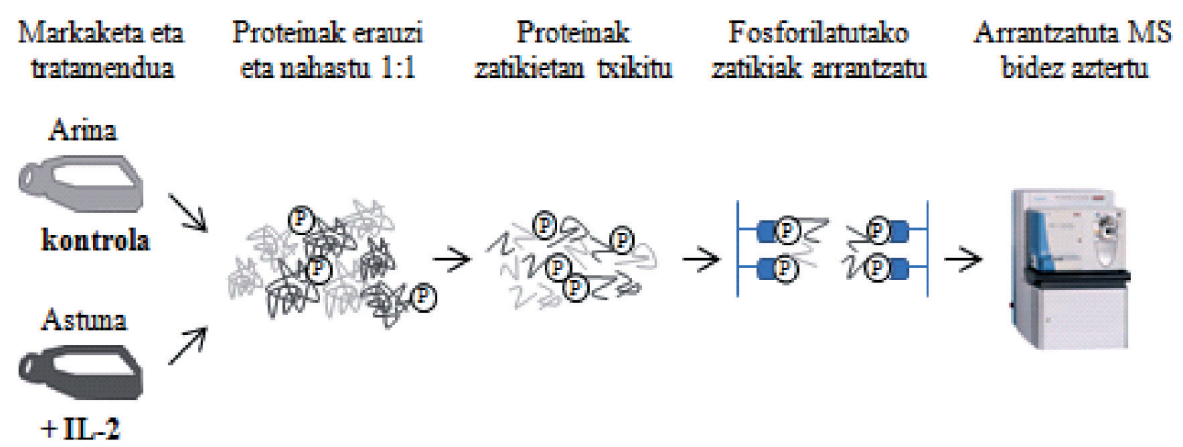

1. irudia. IL-2k T linfozitoen nukleoko proteinen fosforilazioa nola erregulatzen duen aztertzeko ikertzeko lan-fluxua.

Guztira fosforilatutako 8521 aminoazido identifikatu eta kuantifikatu ziren egindako esperimentu beraren 3 saiotan [37]. Oro har, fosforilatuta 
egon ohi diren aminoazidoen proportzioekin bat eginez, gehienbat fosforilatutako serinak topatu genituen, zehazki 7320. Neurri txikiagoan fosfotreoninak identifikatu genituen eta urrienak fosfotirosinak izan ziren (2a irudia), fosfopeptidoak aberasteko $\mathrm{TiO}_{2}$ erabiltzen denean ohikoa izaten den bezala. Fosforilatutako aminoazido hauetako asko jada ezagunak dira eta ondorioz, PhosphoSitePlus datu-basean bilduta daude [38]. Halere, azpimarratzekoa da lan honetan identifikatutako fosforilazio ugari ez daudela datu-base horretan bilduta eta horrenbestez fosforilazio berriak direla onar daiteke (2b irudia).

A

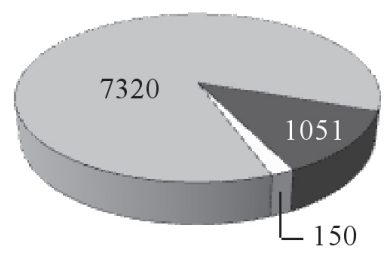

$\square \mathrm{pS} \quad \square \mathrm{pT} \quad \square \mathrm{pY}$
B

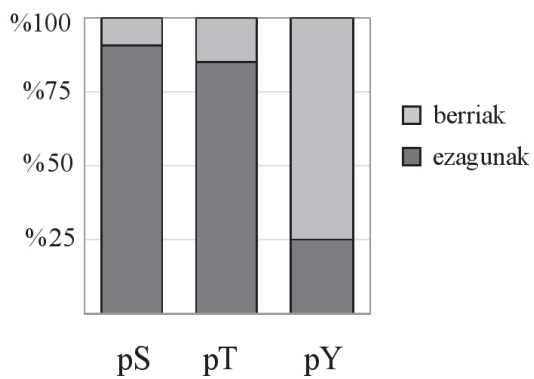

2. irudia. T linfozitoen nukleoan identifikatutako fosfoserinak (pS), fosfotreoninak (pT) eta fosfotirosinak (pY). (A) Guztira identifikatu eta kuantifikatutako pS, pT eta pY aminoazidoen banaketa. (B) Lan honetan aurkitutako fosforilazioen artean PhosphositePlus datu basean deskribatuta daudenen eta ez daudenen arteko proportzioa, hau da, fosforilazio ezagunen eta ezezagunen arteko proportzioa.

Arestian aipatutako 8.000tik gorako fosforilazioak 3.032 proteina ezberdini dagokie. Fosforilatutako proteina horien izaera zehazteko gene-ontologiaren analisia egin zen DAVID deituriko programa erabiliz. Horrela, finkatu genuen zein ziren aberastutako zelula-osagaiak eta biologia-prozesuak [39]. 3a irudian ikus daitekeen bezala, identifikatutako fosfoproteina gehienak nukleoko eskualde ezberdineko proteinak dira, besteak beste nukleolokoak edo nukleo mintzekoak. Izan ere, $3 \mathrm{~b}$ irudian ikus daiteke gure datu sortako fosfoproteinek nukleoko prozesu garrantzitsuetan hartzen dutela parte, hala nola geneen transkripzioan, zelula zikloaren erregulazioan edota RNAren prozesamenduan.

Identifikatutako 8521 fosforilaziotatik, 6145 egindako 3 saioetatik gutxienez $2 \tan$ kuantifikatu ziren. Emaitzak bat etorri ziren eskala handian egiten diren fosfoproteomika-esperimentuen emaitza ohikoekin $[21,33,34,36]$ eta ikusi genuen, antzemandako aminoazido gehienen fosforilazio maila berdintsu mantentzen dela kitzikatutako zein kitzikatu gabeko T-zeluletan (4.irudia, puntu grisak). Halere, azpimarratu beharra dago ehunka aminoazidoren fosforilazio maila nabarmen aldatu zela IL-2rekin 
A

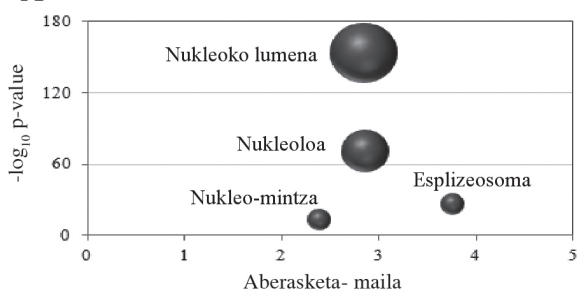

B

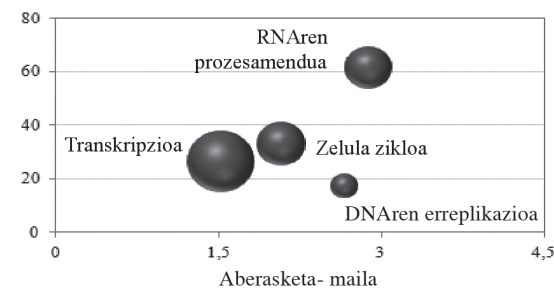

3. irudia. T linfozitoen nukleoan identifikatutako fosfoproteinen artean modu esanguratsuan (p-balioa < 0.05) aberastuta dauden hainbat (A) zelula-osagai eta (B) biologia-prozesu. Puntuen tamainak talde horretan dauden proteinen kopurua adierazten du.

tratatutako T-zeluletan. Zehazki, emaitzek erakusten dute IL-2k estatistikoki nabarmen ( p-balioa $<0.05)$ murrizten dutela 59 fosforilazioren ugaritasuna, eta nabarmen ( $\mathrm{p}$-balioa < 0.05) aregotzen duela 331 fosforilazioren ugaritasuna (4.irudia).

IL-2aren eraginez urriagoak diren fosforilazioak $\mathrm{n}=59$

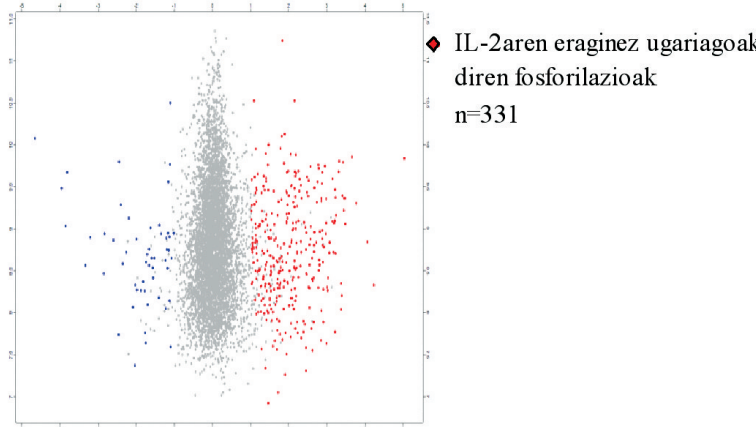

$\log _{2}$ IL-2/kontrol ratioa

4. irudia. IL-2k T linfozitoen nukleoko proteinen fosforilazio mailan duen eragina.

IL-2k induzitutako fosforilazioen artean jada ezagunak diren batzuk aurkitu dira lan honetan. Hain zuzen ere, lan honek berresten du STAT5 proteinaren S780 eta Y694 fosforilatu egiten direla IL-2rekin kitzikatutako T linfozitotan (1.taula) $[23,24]$. Honez gain, emaitzek erakusten dute IL-2ren eraginez MAPK1 eta MAPK3 proteinak sendo fosforilatzen direla T185/Y187 eta T202/Y204 aminoazidotan, hurrenez hurren. Hau bat dator aspaldi egindako aurkikuntza batekin: IL-2k piztutako bidezidorrek MAPK1 eta MAPK3ren fosforilazioa eragiten du eta ondorioz bi kinasak aktibatu egiten dira $[40,41]$. 
1. taula. Jada ezagunak ziren eta lan honetan ere topatu diren IL-2ren menpeko fosforilazio batzuk, kitzikapenaren ondorioz ugariagoak direnak.

\begin{tabular}{l|c|ccc}
\hline \multirow{2}{*}{ Proteina } & \multirow{2}{*}{$\begin{array}{c}\text { Fosforilatutako } \\
\text { aminoazidoa }\end{array}$} & \multicolumn{3}{|c}{ IL-2/Kontrol ratioa } \\
\cline { 3 - 5 } & & 1.erreplika & 2.erreplika & 3.erreplika \\
\hline \multirow{2}{*}{ STAT5A } & Y694 & 7.59 & 10.12 & 6.29 \\
& S780 & 2.19 & 2.11 & - \\
\hline \multirow{2}{*}{ MAPK1 } & Y187 & 17.64 & 15.68 & 7.23 \\
& T185 & 8.95 & 9.21 & 9.74 \\
\hline \multirow{2}{*}{ MAPK3 } & T202 & 10.45 & 10.40 & 4.61 \\
& Y204 & 6.48 & 9.18 & 4.61 \\
\hline
\end{tabular}

Lan honetan identifikatutako IL-2ren menpeko fosforilazio asko PhosphoSitePlus datu-basean agertu agertzen dira. Halere, nabarmentzekoa da ikerkuntza honi esker lehendabizi frogatu dela IL-2ren menpeko erregulazioa pairatzen dutela fosforilazio horietako askok. Besteak beste, emaitzek erakusten dute bai kromatinaren birmoldaketan, bai RNA mezulariaren moztitsasketa prozesuan parte hartzen duten hainbat entzimaren zenbait aminoazido fosforilatu egiten direla IL-2rekin kitzikatutako T-zelulen nukleoan (2. taula).

2. taula. Kromatinaren birmoldaketan eta mRNA.ren moztitsaketan parte hartzen duten zenbait proteinatan gertatzen diren IL-2ren menpeko zenbait fosforilazio, lehenengoz lan honetan aurkituak

\begin{tabular}{|c|c|c|c|c|c|}
\hline \multirow{2}{*}{ Funtzioa } & \multirow{2}{*}{ Proteina } & \multirow{2}{*}{$\begin{array}{c}\text { Fosforilatutako } \\
\text { aminoazidoa }\end{array}$} & \multicolumn{3}{|c|}{ IL-2/Kontrol ratioa } \\
\hline & & & 1.erreplika & 2.erreplika & 3.erreplika \\
\hline \multirow{6}{*}{$\begin{array}{c}\text { Kromatinaren } \\
\text { birmoldaketan } \\
\text { parte hartu }\end{array}$} & \multirow{4}{*}{ MLL } & S261 & 11.33 & 5.51 & - \\
\hline & & S2152 & 3.45 & 3.83 & - \\
\hline & & S2199 & 3.14 & 3.03 & - \\
\hline & & S3039 & 2.57 & 2.35 & 3.17 \\
\hline & KAT6A & S941 & 4.63 & 3.82 & - \\
\hline & KAT7 & S50 & 2.72 & 2.57 & - \\
\hline \multirow{4}{*}{$\begin{array}{l}\text { mRNA.ren } \\
\text { moztitsasketan } \\
\text { parte hartu }\end{array}$} & CWC25 & S337 & 2.17 & 1.89 & - \\
\hline & SRSF11 & S207 & 2.11 & 1.94 & 2.31 \\
\hline & SF3B2 & $\mathrm{S} 343$ & 5.07 & 4.6 & 2.35 \\
\hline & RBM17 & S62 & 3.34 & 11.056 & - \\
\hline
\end{tabular}


2. taulan adierazitakoak adibide gutxi batzuk besterik ez dira. Arestian esan bezala, lan honek T-zelulen nukleoko proteinetan milaka fosforilazio aurkitu ditu eta bereziki garrantzitsua izan da horietako ehunka batzuk IL2ren menpeko erregulazioa pairatzen dutela erakutsi izana. Hortaz ez dago zalantzarik, eta esan dezakegu IL-2k izugarrizko inpaktua duela T-zelulen nukleoko proteinen fosforilazioan.

\section{ONDORIOAK}

SILAC, $\mathrm{TiO}_{2}$ eta masa-espektrometria uztartzen dituen lan-fluxua erabiliz T-zelulen nukleoan fosforilatutako milaka aminoazido identifikatu eta kuantifikatu dira. Hemen aurkeztutako lanak, erakutsi du antzemandako fosforilazio horietatik guztietatik ehunka batzuk IL-2aren menpekoak direla ere. Batzuk ezagunak baziren ere gehienak ez. Hortaz, lortutako emaitza oparoak ikerkuntza berrien abiapuntu izan daitezke. Izan ere, hori da hurrengo erronka nagusia; IL-2k erregulatutako fosforilazioen funtzio biologikoa argitara ematea, horrela zitokinak $\mathrm{T}$ linfozitoen hazkuntza nola bultzatzen duen hobeto ulertzeko. Ondorioz, etorkizunean aukera egongo da immunoterapia eraginkorragoak eta seguruagoak diseinatzeko.

\section{ESKER ONAK}

Lan hau egiteko ondoko erakundeen laguntza jaso dugu: Novo Nordisk Foundation, The Lundbeck Foundation eta The Augustinus Foundation.

\section{BIBLIOGRAFIA}

[1] RESTIFO, N.P., DUDLEY, M.E. and ROSENBERG, S.A. 2012. «Adoptive immunotherapy for cancer: harnessing the T cell response». Nature Reviews Immunology 12, 269-281.

[2] VANNEMAN, M. and DRANOFF, G. 2012. «Combining immunotherapy and targeted therapies in cancer treatment». Nature Reviews Cancer 12,237251.

[3] HIBI, T., INOUE, N., OGATA, H. and NAGANUMA, M. 2003. «Introduction and overview: recent advances in the immunotherapy of inflammatory bowel disease». Journal of Gastroenterology 38, 36-42.

[4] HIRSCH, D.L. and PONDA, P. 2015. «Antigen-based immunotherapy for autoimmune disease: current status». ImmunoTargets and therapy 4, 1-11.

[5] MEI, H.E., SCHMIDT, S. and DOERNER, T. 2012. «Rationale of antiCD19 immunotherapy: an option to target autoreactive plasma cells in autoimmunity». Arthritis Research \& Therapy 14. 
[6] COMTE, D., KARAMPETSOU, M.P. and TSOKOS, G.C. 2015. «T cells as a therapeutic target in SLE». Lupus 24, 351-363.

[7] IWAI, K. et al. 2012. «Extended survival observed in adoptive activated T lymphocyte immunotherapy for advanced lung cancer: results of a multicenter historical cohort study». Cancer Immunology Immunotherapy 61, 1781-1790.

[8] TCHOU, J. et al. 2012. «Mesothelin, a novel immunotherapy target for triple negative breast cancer». Breast Cancer Research and Treatment 133, 799804.

[9] ROSENBERG, S.A. et al. 1994. «Treatment of patients with metastatic melanoma with autologous tumor-infiltrating lymphocytes and interleukin-2». Journal of the National Cancer Institute 86, 1159-1166.

[10] ROSENBERG, S.A. 2014. «IL-2: The First Effective Immunotherapy for Human Cancer». Journal of Immunology 192, 5451-5458.

[11] YARKONI, S., SAGIV, Y., KAMINITZ, A. and ASKENASY, N. 2009. «Interleukin 2 targeted therapy in inflammatory bowel disease». Gut 58, 1705-1706.

[12] WALDMANN, T.A. 2006. «The biology of interleukin-2 and interleukin-15: implications for cancer therapy and vaccine design». Nature Reviews Immunology 6, 595-601.

[13] TANG, Q. 2015. «Therapeutic Window of Interleukin-2 for Autoimmune Diseases». Diabetes 64, 1912-1913.

[14] KLATZMANN, D. and ABBAS, A.K. 2015. «The promise of low-dose interleukin-2 therapy for autoimmune and inflammatory diseases». Nature Reviews Immunology 15, 283-294.

[15] FEHERVARI, Z., YAMAGUCHI, T. and SAKAGUCHI, S. 2006. «The dichotomous role of IL-2: tolerance versus immunity». Trends in Immunology 27, 109-111.

[16] LENARDO, M.J. 1991. «Interleukin-2 programs mouse alpha-beta-lymhpocytes T for apoptosis ». Nature 353, 858-861.

[17] JOHNSTON, J.A. et al. 1995. «Tyrosine phosphorylation and activation of STAT5, STAT3, and Janus kinases by interleukin-2 and interleukin-15». Proceedings of the National Academy of Sciences of the United States of America 92, 8705-8709.

[18] MIYAZAKI, T. et al. 1994. «Functional activation of JAK1 and JAK3 by selective association with IL-2 receptor subunits». Science 266, 1045-1047.

[19] REMillard, B., PETRILlO, R., MASLINSKI, W., TSUDO, M., STROM, T.B., CANTLEY, L. and VARTICOVSKI, L. 1991. «Interleukin-2 receptor regulates activation of phosphatidylinositol 3-kinase». Journal of Biological Chemistry 266, 14167-14170.

[20] OSINALDE, N. et al. 2011. " Interleukin-2 signaling pathway analysis by quantitative phosphoproteomics». Journal of Proteomics 75, 177-191.

[21] OSINALDE, N., SANCHEZ-QUILES, V., AKIMOV, V., GUERRA, B., BLAGOEV, B. and KRATCHMAROVA, I. 2015. «Simultaneous dissection 
and comparison of IL-2 and IL-15 signaling pathways by global quantitative phosphoproteomics». Proteomics 15, 520-531.

[22] DYBKAER, K., IQBAL, J., ZHOU, G., GENG, H., XIAO, L., SCHMITZ, A., D'AMORE, F. and CHAN, W.C. 2007. «Genome wide transcriptional analysis of resting and IL2 activated human natural killer cells: gene expression signatures indicative of novel molecular signaling pathways». Bmc Genomics $\mathbf{8}$.

[23] BEADLING, C., GUSCHIN, D., WITTHUHN, B.A., ZIEMIECKI, A., IHLE, J.N., KERR, I.M. and CANTRELL, D.A. 1994. « Activation of JAK kinases and STAT proteins by interleukin-2 and interferon-alpha, but not the T-cell antigen receptor, in human T-lymphocytes». Embo Journal 13, 56055615.

[24] FRANK, D.A., ROBERTSON, M.J., BONNI, A., RITZ, J. and GREENBERG, M.E. 1995. «Interleukin-2 signaling involves the phosphorylation of STAT proteins». Proceedings of the National Academy of Sciences of the United States of America 92, 7779-7783.

[25] Larsen, M.R., Thingholm, T.E., Jensen, O.N., Roepstorff, P. and Jorgensen, T.J.D. 2005. «Highly selective enrichment of phosphorylated peptides from peptide mixtures using titanium dioxide microcolumns». Molecular \& Cellular Proteomics 4, 873-886.

[26] THINGHOLM, T.E., JENSEN, O.N., ROBINSON, P.J. and LARSEN, M.R. 2008. «SIMAC sequential elution from IMAC, a phosphoproteomics strategy for the rapid separation of monophosphorylated from multiply phosphorylated peptides». Molecular \& Cellular Proteomics 7, 661-671.

[27] POSEWITZ, M.C. and TEMPST, P. 1999. «Immobilized galliumIII affinity chromatography of phosphopeptides». Analytical Chemistry 71, 2883-2892.

[28] NOBLES, K.N. et al. 2011. «Distinct Phosphorylation Sites on the beta2Adrenergic Receptor Establish a Barcode That Encodes Differential Functions of beta-Arrestin». Science Signaling 4.

[29] ZHOU, Y.J. et al. 1997. «Distinct tyrosine phosphorylation sites in JAK3 kinase domain positively and negatively regulate its enzymatic activity. Proceedings of the National Academy of Sciences of the United States of America 94, 13850-13855.

[30] DEPHOURE, N., GOULD, K.L., GYGI, S.P. and KELLOGG, D.R. 2013. «Mapping and analysis of phosphorylation sites: a quick guide for cell biologists». Molecular Biology of the Cell 24, 535-542.

[31] JENSEN, O.N. 2006. «Interpreting the protein language using proteomics». Nature Reviews Molecular Cell Biology 7, 391-403.

[32] ONG, S.E., BLAGOEV, B., KRATCHMAROVA, I., KRISTENSEN, D.B., STEEN, H., PANDEY, A. and MANN, M. 2002. «Stable isotope labeling by amino acids in cell culture, SILAC, as a simple and accurate approach to expression proteomics». Molecular \& Cellular Proteomics 1, 376-386.

[33] KRUEGER, M., KRATCHMAROVA, I., BLAGOEV, B., TSENG, Y.-H., KAHN, C.R. and MANN, M. 2008. «Dissection of the insulin signaling 
pathway via quantitative phosphoproteomics». Proceedings of the National Academy of Sciences of the United States of America 105, 2451-2456.

[34] BLAGOEV, B., KRATCHMAROVA, I., ONG, S.E., NIELSEN, M., FOSTER, L.J. and MANN, M. 2003. «A proteomics strategy to elucidate functional protein-protein interactions applied to EGF signaling». Nature Biotechnology 21, 315-318.

[35] FRANCAVILLA, C. et al. 2013. «Functional Proteomics Defines the Molecular Switch Underlying FGF Receptor Trafficking and Cellular Outputs». Molecular Cell 51, 707-722.

[36] KRATCHMAROVA, I., BLAGOEV, B., HAACK-SORENSEN, M., KASSEM, M. and MANN, M. 2005. «Mechanism of divergent growth factor effects in mesenchymal stem cell differentiation. Science 308, 14721477.

[37] OSINALDE, N. et al. 2016. «Nuclear Phosphoproteomic Screen Uncovers ACLY as Mediator of IL-2-induced Proliferation of CD4+ T lymphocytes». Molecular \& Cellular Proteomics 15, 2076-2092.

[38] HORNBECK, P.V., ZHANG, B., MURRAY, B., KORNHAUSER, J.M., LATHAM, V. and SKRZYPEK, E. 2015. «PhosphoSitePlus, 2014: mutations, PTMs and recalibrations». Nucleic Acids Research 43, D512-D520.

[39] HUANG, D.W., SHERMAN, B.T. and LEMPICKI, R.A. 2009. «Systematic and integrative analysis of large gene lists using DAVID bioinformatics resources». Nature Protocols 4, 44-57.

[40] GADINA, M., STANCATO, L.M., BACON, C.M., LARNER, A.C. and O'SHEA, J.J. 1998. «Cutting edge: Involvement of SHP-2 in multiple aspects of IL-2 signaling: Evidence for a positive regulatory role». Journal of Immunology 160, 4657-4661.

[41] ARNAUD, M., CRONIN, C., DEON, C., LOYAUX, D. and BERTOGLIO, J. 2004. «Phosphorylation of Grb2-associated binder 2 on serine 623 by ERK MAPK regulates its association with the phosphatase SHP-2 and decreases STAT5 activation». Journal of Immunology 173, 3962-3971. 